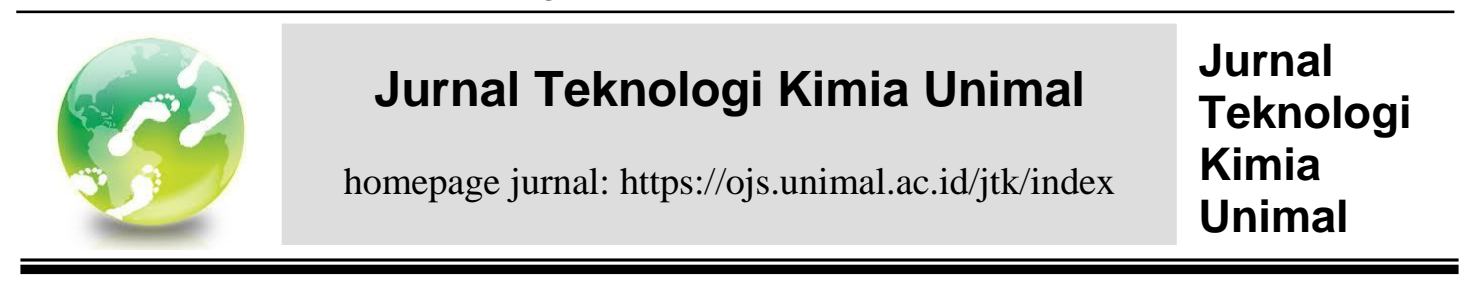

\title{
EFEKTIVITAS PRODUK ANTI SEPTIK ALAMI DALAM MENCEGAH PENYEBARAN COVID-19
}

\author{
Zainuddin Ginting ${ }^{1}$, Ishak ${ }^{1}$, Syamsul Bahri ${ }^{1}$ \\ ${ }^{1}$ Program Studi Teknik Kimia, Fakultas Teknik, Universitas Malikussaleh, \\ Kampus Utama Jl. Cot Tengku Nie, Reuleut, Muara Batu, Aceh Utara, \\ Aceh , Indonesia. E-mail: zginting@ unimal.ac.id
}

\begin{abstract}
Abstrak
Kegiatan Penerapan Ipteks bagi masyarakat (IbM) ini bertujuan untuk memberikan keterampilan tentang pengolahan minyak nilam menjadi beberapa jenis olahan tambahan pada pembuatan gel antiseptik Berbasis Teknologi Tepat Guna. Pengabdian akan dilaksanakan di Desa Kilometer VIII, Kecamatan Simpang Keuramat, Kabupaten Aceh Utara dengan sasaran mitra: Pemilik kebun tanaman nilam (Mitra 1) dan kelompok taruna (Mitra 2) di Desa Kilometer VIII, Kecamatan Simpang Keuramat, Kabupaten Aceh Utara. Kedua mitra ini akan diperkenalkan teknologi pengolahan gel antiseptik (hand sanitizer). Perlakuan yang akan diterapkan dalam IbM ini terdiri dari sosialisasi dan pengenalan teknologi pembuatan gel antiseptik (hand sanitizer) dimana minyak nilam yang ada di Desa Kilometer VIII, Kecamatan Simpang Keuramat, Kabupaten Aceh Utara hanya langsung dijual kepada pengumpul di Medan maupun kepada pembeli langsung dari luar negeri. Namun, harga produk ditentukan oleh pembeli yang tentu saja sering merugikan petani. Realisasi penerapan kegiatan ini akan dilakukan melalui sosialisasi manfaat minyak nilam untuk dijadikan usaha sampingan, serta pengenalan teknologi olahan minyak nilam menjadi gel antiseptik. Program olahan minyak nilam berbasis teknologi tepat guna akan dilakukan beberapa kegiatan yaitu : pembekalan teori, pengenalan teknologi, pelatihan, dan pengujian. Minyak nilam dari mitra 1 akan dimanfaatkan oleh mitra 2, dan saling bekerja sama dalam memproduksi gel antiseptik, peluang bisnis dan manfaat ekonomis produk. Selain itu perlu juga dikaji lebih lanjut tentang pengembangan produk gel antiseptik sebagai salah satu produk usaha baru kelompok taruna di Desa Kilometer VIII, Kecamatan Simpang Keuramat, Kabupaten Aceh Utara.
\end{abstract}

Kata kunci: gel antiseptik, minyak nilam, mitra nilam Aceh, patchouli alcohol

\section{Pendahuluan}

Nilam Aceh (pogostemon cablin benth) merupakan nilam unggul dengan kualitas terbaik di dunia karena menghasilkan minyak dengan rendemen 3\% dan 
kandungan patchouli alcohol (PA) di atas 30\% (Faizal, 2017). Tanaman nilam yang mengandung minyak atsiri terdapat pada seluruh bagian tanaman seperti akar, batang, cabang, dan daun. Bagian akar dan batang tanaman nilam umumnya memiliki mutu dan rendemen minyak yang lebih rendah.

Minyak nilam selama ini hanya diolah dan dipasarkan sebatas minyak dengan kandungan patchouli alcohol 30-34\% saja, tanpa ada variasi turunan produk yang dihasilkan, padahal banyak sekali produk turunan yang dapat diolah menggunakan minyak nilam seperti parfum, pengharum ruangan, lilin aromaterapi bahkan gel antiseptik, sehingga dapat menunjang perekonomian masyarakat.

Hand Sanitizer merupakan pembersih tangan yang memiliki kemampuan antibakteri dalam membunuh bakteri. Hand sanitizer gel merupakan pembersih tangan berbentuk gel yang berguna untuk membersihkan atau menghilangkan kuman pada tangan, mengandung bahan aktif alkohol 60\% (Hapsari, 2015). Produk gel antiseptik (Hand sanitizer) yang berasal dari bahan baku minyak nilam belum terlalu populer di Desa Kilometer VIII, Kecamatan Simpang Keuramat, Kabupaten Aceh Utara, padahal kandungan patchouli alcohol yang terkandung dalam minyak nilam dapat menjadikan bahan pengganti alkohol sintetik pada umumnya sehingga antiseptik yang diproduksi akan lebih aman dan baik untuk kesehatan, oleh karena itu program Iptek bagi masyarakat ini memberikan cara pembuatan (teknologi) yang sederhana dalam pembuatan gel antiseptik (Hand sanitizer) minyak nilam.

Adanya upaya mengkonversi bahan baku minyak nilam menjadi gel antiseptik (Hand sanitizer) sangat menjanjikan ditambah lagi dalam kondisi pandemi Covid-19 saat ini, hal ini akan memberi nilai tambah bagi kelompok taruna desa untuk meningkatkan perekonomiannya. Dimana selama ini minyak nilam kurang dimanfaatkan sehingga membuat daya jual minyak nilam rendah. Kedua mitra ini diyakini akan saling bersinergi dalam pelaksanaan kegiatan nantinya.

Hingga saat ini, produk minyak nilam dijual kepada pengumpul di Medan maupun kepada pembeli langsung dari luar negeri. Namun, harga produk ditentukan oleh pembeli yang tentu saja sering merugikan petani. Sehingga, 
meskipun Aceh adalah penghasil nilam terbaik dan terbesar di dunia, namun kehidupan petaninya masih relatif miskin.

Masyarakat Desa Kilometer VIII, Kecamatan Simpang Keuramat, Kabupaten Aceh Utara, masih belum menyadari dan masih belum mengerti jika minyak nilam yang mereka suling ternyata memiliki manfaat yang besar untuk kesehatan, dan untuk berbagai macam produk berbahan baku minyak nilam lainnya. Rendahnya pengetahuan masyarakat dan pemuda setempat membuat tidak adanya inovasi akan produk berbahan baku minyak nilam. Pemanfaatan minyak nilam yang saat ini sangat berpotensi untuk meningkatkan nilai jual minyak nilam dimasa pandemi Covid-19 yaitu dengan menjadikan minyak nilam sebagai gel antiseptik alami (Hand sanitizer) guna mencegah penyebaran dan penularan sesuai dengan protokol kesehatan Covid-19. pembuatan gel antiseptik (Hand sanitizer) minyak nilam yang dibimbing oleh tim pelaksana kegiatan, menjadikan minyak nilam sebagai komoditi lokal yang memiliki nilai jual yang lebih tinggi.

Solusi yang ditawarkan oleh tim pelaksana kegiatan pengabdian kepada kelompok taruna desa ini, yaitu bekerja sama dengan petani nilam dan penyuling minyak nilam, selanjutntnya diberi keterampilan dalam membuat produk minyak nilam berupa gel antiseptik alami (Hand sanitizer). Home industry ini nantinya juga dapat dijadikan usaha sampingan masyarakat untuk meningkatkan perekonomian rumah tangga dan meningkatkan pendapatan masyarakat setempat di era new normal saat ini

\section{Bahan dan Metode}

Metode pelaksaan yang di lakukan pada kegiatan ini diawali dengan pemberian surat izin kepada geuchik Desa Kilometer VIII, Kecamatan Simpang Keuramat, Kabupaten Aceh Utara untuk dilaksanakannya kegiatan ini di desa tersebut. 


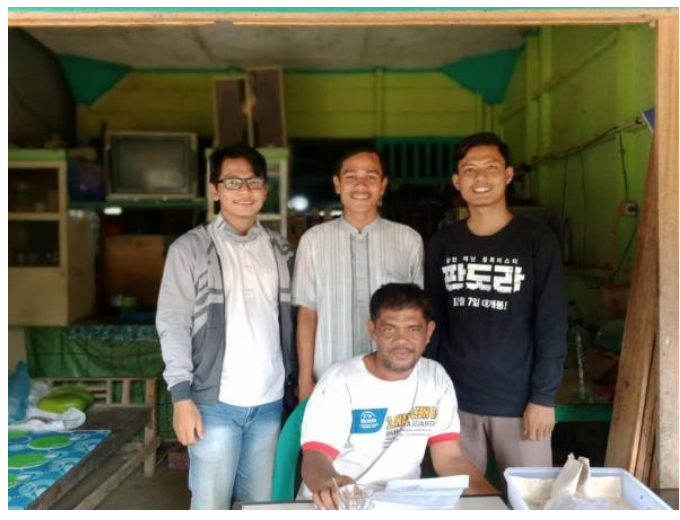

Gambar 1. Pemberian surat izin kepada Geuchik Desa Kilometer VIII, Kecamatan Simpang Keuramat, Kabupaten Aceh Utara

Kemudian di lakukan pembuatan gel antiseptik di Laboratorium Jurusan Teknik Kimia, Universitas Malikussaleh, yang diawali dengan mempersiapkan alat-alat dan bahan-bahan yang digunakan.

Bahan-bahan yang digunakan yaitu minyak nilam, karbopol 940, gliserin, metil paraben, tritonalamine (TEA), propilen glikol, dan aquades. Peralatan yang digunakan yaitu gelas ukur $1000 \mathrm{ml}$, beaker glass, gelas ukur 50ml dan 25ml, batang pengaduk, dan botol kaca.

Proses pembuatan gel antiseptik (Hand sanitizer) minyak nilam diawali dengan karbopol 940 sebanyak 1 gr didispersikan dengan $30 \mathrm{ml}$ aquadest panas bersuhu $70^{\circ} \mathrm{C}$ di dalam cawan porselin. Lalu diaduk pada suhu ruangan sampai terbentuk massa gel. Kemudian, ditambahkan Tritonalamine sebanyak $1 \mathrm{~mL}$ ke dalam basis gel lalu diaduk hingga terbentuk massa gel transparan. Ditimbang metil paraben 0,18 gr dan dilarutkan dengan $5 \mathrm{~mL}$ aquadest di dalam gelas kimia $10 \mathrm{~mL}$. Basis gel dipindahkan ke dalam gelas kimia $150 \mathrm{~mL}$, kemudian ditambahkan metil paraben yang telah dilarutkan dan diaduk hingga homogen. Ditambahkan secara perlahan propilen glikol $5 \mathrm{~mL}$; gliserin $10 \mathrm{~mL}$ dan minyak nilam ke dalam basis gel dan diaduk hingga homogen. Setelah semua campuran homogen lalu ditambahkan aquadest sampai volume gel menjadi $100 \mathrm{~mL}$. Kemudian gel dipindahkan ke dalam botol. Lalu disimpan pada tempat yang gelap dan dingin sampai dilakukan pengujian. 

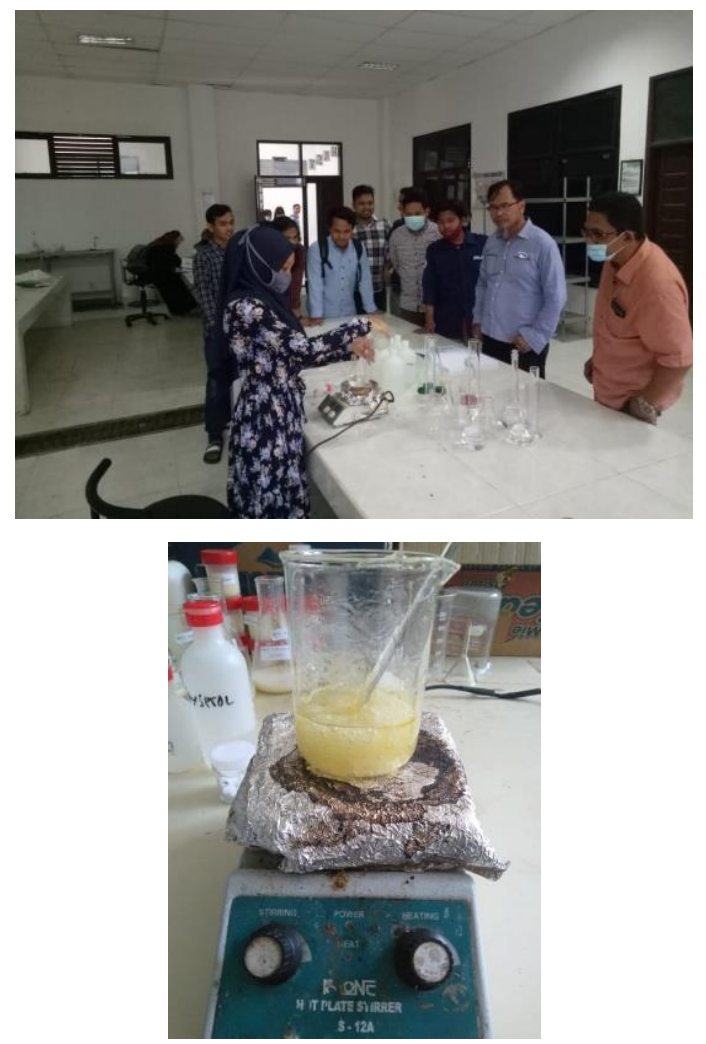

Gambar 2. Pembuatan Gel Antiseptik (hand sanitizer)

Setelah dilakukan pembuatan gel antiseptik (hand sanitizer), dilakukan kegiatan pengabdian kepada masyarakat Desa Kilometer VIII, Kecamatan Simpang Keuramat, Kabupaten Aceh Utara dengan membantu pemilik kebun tanaman nilam melakukan pelabelan tanaman nilam yang diberikan pemerintah Aceh Utara. Lalu dilakukan penyuluhan dengan memberi penjelasan mengenai manfaat minyak nilam sebagai antiseptik alami ditengan pandemi Covid-19, memberi pelatihan dan pendampingan proses pembuatan produk antiseptik alami dari minyak nilam, cara mempromosikan produk olahan home industry Desa Kilometer VIII, Kecamatan Simpang Keuramat, Kabupaten Aceh Utara, serta masyarakat bisa langsung mendapatkan hasil nyata produk gel antiseptik alami hasil olahan dari minyak nilam. 


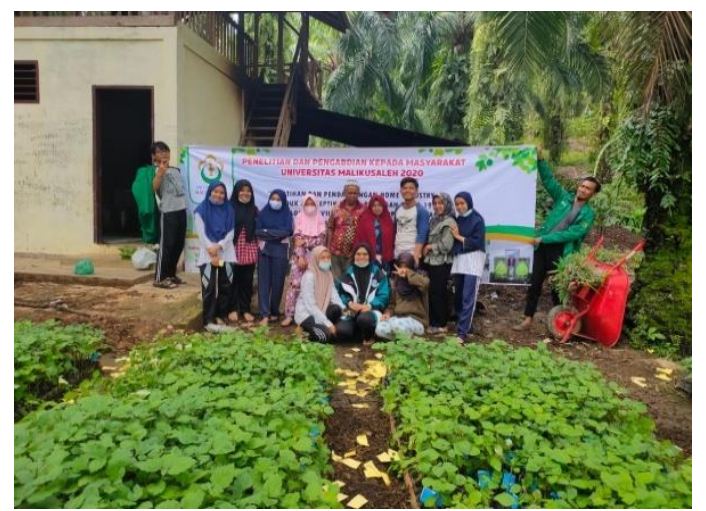

Gambar 3. Pelabelan Tanaman Nilam

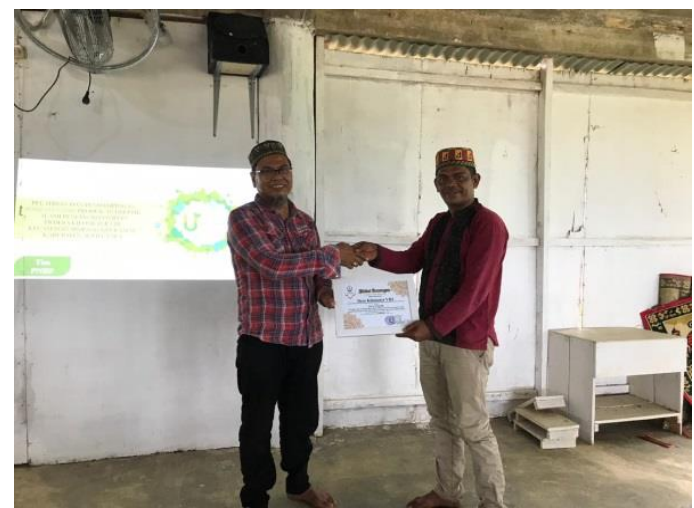

(a)

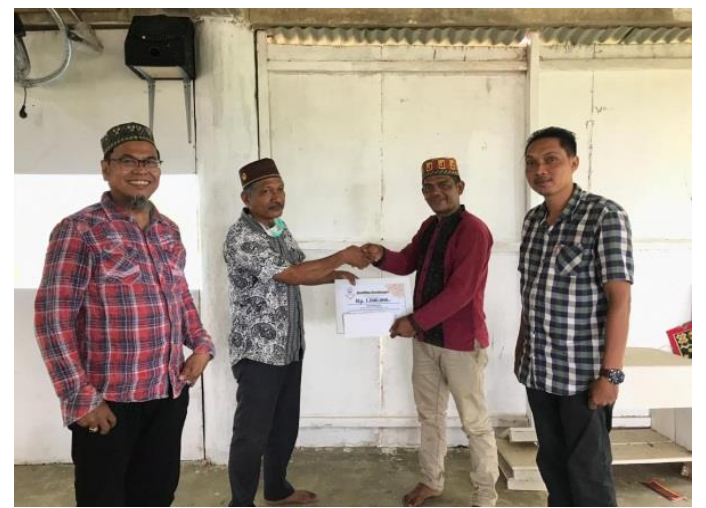

(b) 


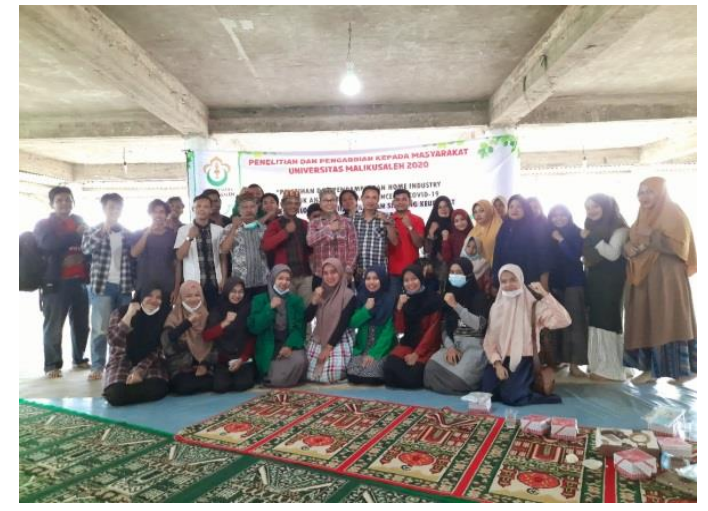

(c)

Gambar 3.(a)(b)(c) Pelatihan dan Pengabdian Produk Antiseptik Alami

\section{Hasil dan Luaran Yang Dicapai}

Evaluasi kegiatan yang sudah dilakukan hasilnya adalah berhasil dengan indikator keberhasilannya adalah masyarakat setempat sangat mendukung program dan sangat aktif dalam berbagai hal, membantu menyediakan lokasi pembuatan gel antiseptik (hand sanitizer) secara berkelompok serta permintaan dan keputusan bersama agar program ini berlanjut. Sebelum adanya kegiatan pengabdian kepada masyarakat tentang pembuatan gel antiseptik (hand sanitizer) ini, masyarakat setempat tidak memproduksi produk tersebut dan setelah ada program pengabdian ini mitra sudah bisa memproduksi gel antiseptik (hand sanitizer) minyak nilam.

Geuchik Desa Kilometer VIII, Mahyeddin Abu Bakar mengucapkan terima kasih atas kegiatan pengabdian ini, karena desa tersebut memiliki empat hektar tanaman nilam produktif dan empat hektar lagi siap tanam dengan menghasilkan minyak nilam terbaik nomor dua di dunia, karena minyak nilamnya mengandung Patchouli Alcohol lebih dari 30\%. Beliau berharap, kegiatan pengabdian ini tidak hanya dilakukan berupa pelatihan, akan tetapi terus dilakukan pendampingan produk-produk home industri turunan dari minyak nilam. Meskipun pelatihan ini telah selesai, kegiatan pendampingan dapat dilakukan berupa optimalisasi alat penyulingan yang ada, membuat sistem promosi dan pemasaran produk agar dikenal masyarakat luas serta terus melakukan diskusi dan komunikasi. Sehingga kedepan bisa menghasilkan produk 
turunan dari minyak nilam lebih banyak lagi yang menjadi produk unggulan dan memiliki ciri khas desa Kilometer VIII.

Kegiatan pengabdian ini sempat dirilis dan dipublikasikan di beberapa media, di antaranya:

1. Media layarberita.com dengan link https://layarberita.com/02/12/2020/dosenfakultas-tehnik-unimal-bangkitkan-home-industri-produk-unggulan/

2. Media unimalnews dengan link http://news.unimal.ac.id/index/single/1958 /tingkatkan-kualitas-produk-unggulan-desa-dosen-ft-beri-pelatihan-dan pendampingan

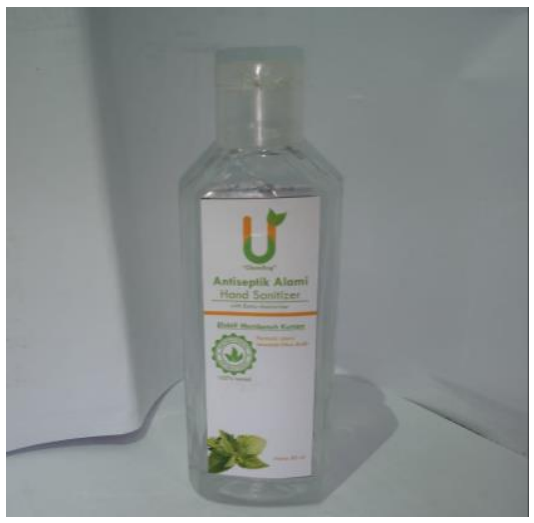

(a)

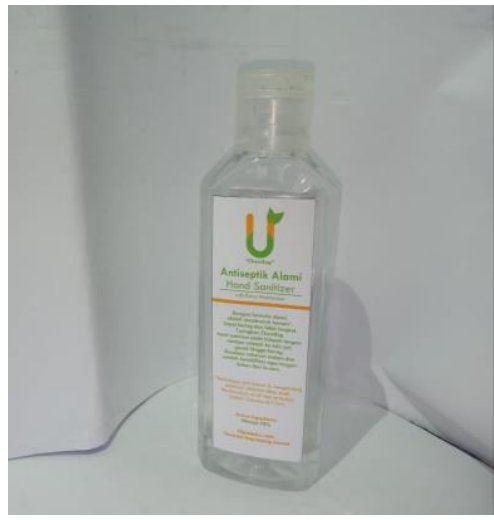

(b)

Gambar 4.(a)(b) Produk Antiseptik Alami

\section{Simpulan dan Saran}

Dari hasil pengabdian yang sudah dilakukan dapat diambil kesimpulan sebagai berikut: 
1. Mitra terdiri dari pemilik kebun tanaman nilam dan kelompok taruna Desa Kilometer VIII, Kecamatan Simpang Keuramat, Kabupaten Aceh Utara.

2. Kelompok taruna dan masyarakat mengerti akan manfaat lain dari minyak nilam.

3. Proses pengembangan produk yang dilaksanakan adalah melalui pelatihan pembuatan gel antiseptik.

4. Peserta bertambah ilmu pengetahuannya tentang pemanfaatan hasil pertanian, pengelolaan produk olahan minyak nilam.

5. Peserta juga mendapatkan gel antiseptik hasil olahan dari minyak nilam.

Antiseptik alami yang dihasilkan oleh kelompok taruna dan masyarakat

Desa Kilometer VIII, Kecamatan Simpang Keuramat, Kabupaten Aceh Utara perlu pengurusan izin usaha serta mengembangkan kembali olahan minyak nilam.

\section{Daftar Pustaka}

1. BAPPEDA. (2015). Sistem Inovasi Industri Nilam Aceh. Aceh: Badan Perencanaan Pembangunan Daerah.

2. Faizal. (2017). "Karakteristik Simplisia dan Isolasi serta Analisis Komponen Minyak Atsiri dari Daun Nilam (Pogostemon Cabin Benth) Asal Aceh Tenggara”. Universitas Sumatera Utara: Medan , 117-128.

3. Hapsari, D. N. (2015).Pemanfaatan Ekstrak Daun Sirih (Piper Betle Linn) Sebagai Hand Sanitizer.Skripsi.Poltekkes Kemenkes Yogyakarta.

4. Siti. S. (2020). Covid-19 and Indonesia. Jakarta: Universitas Indonesia.

5. Statistik, B. P. (2018). Statistik Perdagangan Luar Negeri. BPS Jakarta

6. Yuhono, J. S. (2017). Strategi Peningkatan Rendemen dan Mutu Minyak dalam Agribisnis Nilam. Balittro Bogor. Perkembangan Teknologi TRO. $69-71$ 